\title{
Commentary and Debate
}

\section{COMMENTS ON WANDERER'S ARTICLE ON RIOT SEVERITY AND ITS CORRELATES}

A number of findings reported in a recent article, "An Index of Riot Severity and Some Correlates" (Wanderer 1969), are suspect on several accounts. Wanderer constructs an index of riot severity, then correlates the scale values with selected community characteristics. I have no objection to his design of the Index; however, his attempt to relate community characteristics to riot severity leaves much to be desired in the way of conceptualization and methodology.

First, excluding the police preparation measures, which one can reasonably expect to be related to the response by law enforcement to a disturbance and to the resulting severity of the disorder, Wanderer presents little in the way of theoretical justification for his choice of community characteristics. Why, for example, should percentage increase of nonwhites in the 1950-60 decade be related to riot severity? Wanderer cites the study by Lieberson and Silverman (1965) as having guided his selection of community characteristics; yet it is unclear why one would expect variables which were justified in terms of a possible relation to the location of a riot to explain also the severity of a disorder. Moreover, Lieberson and Silverman reported findings for a much wider range of community characteristics (racial differences in occupation, unemployment rates, store ownership in the ghetto, and community political structure) than Wanderer considers, so one is still left to ponder upon the rationale which governed his selection of explanatory variables.

Second, excluding the police preparation measures, Wanderer reports significant correlations for two of the fourteen community characteristics which he considers. When the pickings are so meager, an investigator is particularly obliged to explain that we are not simply witnessing chance correlations due to sampling error and that the findings, in fact, support some coherent account of the causes of riot severity. Wanderer's failure to address this problem is especially unfortunate since one of the two significant associations was with a housing variable. He examines nine housing characteristics, finds only one (percentage living in newer than ten-year-old dwellings) to be correlated with riot severity. An obvious inquiry in this circumstance is to ascertain what is tapped by this measure which is not captured by any other housing variable. Yet, this question is not considered.

Third, on the basis of the two significant correlations, Wanderer concludes: "It has been shown that while certain variables do not correlate with the presence or absence of riots in American cities, they do correlate with riot severity. Such variables are more influential in determining the severity of a riot, once it has begun, than they are in determining the outbreak of that riot" (p. 505). This is an entirely unwarranted statement. Wanderer is comparing findings by Lieberson and Silverman on the causes of riots with his own on severity, although the two studies covered different 
time periods and disorders which were vastly different in character. Lieberson and Silverman examined the causes of disturbances during the years 1913-63 which could be classified as "Negro-white race riots" (Lieberson and Silverman 1965, p. 887). Wanderer draws his material on riot severity from the 1967 disorders which were largely instances of Negro rebellion, not interracial violence. One cannot assume, a priori, that these two forms of racial violence which occurred in different time intervals are alternative faces of the same phenomenon. The community characteristics which Wanderer considers to be unrelated to an outbreak of racial violence may well be related to the location of the 1967 disorders. The community characteristics which he argues are related to the severity of a disturbance may be unrelated to the severity of the earlier, interracial riots. His extrapolations are simply unjustified.

Unfortunately, the situation is even worse. Neither the single housing variable which Wanderer finds to be correlated with the severity of a disturbance (percentage living in newer than ten-year-old dwellings) nor the remaining variable for which he indicates a significant correlation (percentage increase of nonwhites) were used by Lieberson and Silverman. They report findings for only one measure of housing quality, the census category "dilapidated." Among the housing variables investigated by Wanderer, "percentage of units with substandard plumbing" appears closest in nuance to the earlier study's housing measure. This variable, incidentally, is reported by Wanderer as being uncorrelated with the severity of a disorder.

With respect to the second community characteristic, "percentage increase of nonwhites," a careful reading of the Lieberson and Silverman paper reveals that they used the measure $\left(N_{t+1}-N_{t}\right) / N_{t}$, where $N_{t}$ is the numerical size of the nonwhite population in year $t$. Wanderer, however, uses the measure "percentage increase of nonwhites in the total population" (p. 502)-presumably, percentage nonwhite in 1960 minus percentage nonwhite in 1950, perhaps standardized on the 1950 figure. On the Lieberson and Silverman index, a city which was 5 percent nonwhite in 1950,5 percent nonwhite in 1960 , but experienced a 50 percent increase in total population during the decade would have the value .50; on Wanderer's Index (standardized or unstandardized versions), the value would be zero. Lieberson and Silverman's measure is an appropriate statistic for a social disorganization thesis, which is what they argue. It is unclear just what Wanderer's Index is tapping, but it is evident that we have a very different animal here.

Fourth, Wanderer's methodology appears guaranteed to discard a maximum amount of information in the data. Since the seventy-five cities are classified into eight scale types on riot severity, Wanderer chose to correlate the scale types with community characteristics. His procedure was to average the city values on an independent variable within each scale type, rank order the averages, then compute a Spearman correlation over the eight observations. The difficulty with this approach is that by averaging city values within a scale type, the possibly substantial within-category variation is ignored. In general, a classification is meaningful if it tends to group like values on a variable, with the result that the categories "explain" a sig- 
nificant proportion of the total variation in the variable. If the category averages are substantially the same, however, then the variation is largely within category and remains unexplained by the classification. In this circumstance, a ranking of the category averages is equivalent to ranking values which are not significantly different from one another.

To investigate the effects of Wanderer's methodology on his findings, I collected data on city characteristics using the sources cited in his article. ${ }^{1}$ The validity of the classification on the single housing variable reported by him to be correlated with riot severity was examined by performing a oneway ANOVA on this variable. The result was not significant at the .10 level $\left(F_{7,60}=1.19\right) .{ }^{2}$ Consequently, Wanderer's classification is irrelevant, since the variation is essentially within category. The correct procedure would be to rank the cities on the independent variable, assign identical average values on the dependent variable to cities in each scale type, then compute a correlation over the seventy-five observations. ${ }^{3}$ Employing this procedure, I computed a Spearman correlation between riot severity and percentage living in newer than ten-year-old dwellings which equals -.10 (insignificant at the .10 level) in contrast to the -.86 value reported by Wanderer.

Fifth, Wanderer's use of the Spearman statistic is unfortunate in that it prevented him from investigating the possibility of a spurious relation between riot severity and the community characteristics. He writes: "Once a riot takes place, the greater the percentage increase of nonwhites, the greater the severity of the riot" (p. 502). I have no objection to this as a descriptive statement, but the intimation in the article is that a causal relation somehow exists between change in percentage nonwhite and riot severity. This inference, however, loses support once an appropriate control is introduced. Since the riot-severity scale uses items such as "called the state police" and "called national guard," the numerical size of the Negro population would seem to be an obvious community characteristic for investigation. Communities such as Mount Clemens, Michigan (nonwhite population equal to 2,500 in 1960), or Elgin, Illinois (nonwhite population equal to $1,700)$, would be hard pressed to mount a disorder worthy of national guard attention. Due to the limitations of his methodology, however (the Spearman coefficient has no partial), Wanderer was not able to control for Negro population size and was probably discouraged thereby from delving into the conceptual question of spurious effects.

To pursue this line of inquiry, I calculated product-moment correlations

1 Using the sources reported by Wanderer, I was able to obtain information on seventyfour of the seventy-five cities included in the severity scale. No reference was found to Wyandanch, N.Y., in either the County and City Data Book, 1967 (U.S. Bureau of the Census 1967) or in the 1960 Census of Population (U.S. Bureau of the Census 1960).

2 Wanderer used category medians for the housing variable, although the skewness of the distribution is minor. I replicated the ANOVA using city ranks and obtained the same result-the classification is insignificant at the .10 level $\left(F_{7,66}=0.94\right)$.

See Siegel (1956, pp. 201-11). 
with riot severity, while the second characteristic becomes insignificant when the numerical size of the Negro population, a conceptually prior variable, is controlled.

\section{University of Wisconsin}

Seymour Spilerman

\section{REFERENCES}

Lieberson, Stanley, and Arnold R. Silverman. 1965. "The Precipitants and Underlying Conditions of Race Riots." American Sociological Review 30 (December): 887-98.

Siegel, Sidney. 1956. Non-Parametric Statistics. New York: McGraw-Hill.

U.S. Bureau of the Census. 1960. Census of Population. Washington, D.C.: Government Printing Office.

. 1967. County and City Data Book, 1967. Washington, D.C.: Government Printing Office.

Wanderer, Jules J. 1969. "An Index of Riot Severity and Some Correlates." American Journal of Sociology 74 (March):500-505.

\section{THE AUTHOR REPLIES}

The bulk of Mr. Spilerman's substantive criticism seems to be based upon two errors. The first concerns what he thought was the title of my paper; the second concerns what he assumes was the intention of my research.

Although he gave my paper careful reading, Spilerman apparently neglected to read correctly its title. He incorrectly believed that "An Index of Riot Severity and Some Correlates" (Wanderer 1969) was titled "An Index of Riot Severity and Its Correlates." My intention is clearly expressed in the original title and the selection of the word "some." The rationale for selecting "select" variables is discussed on page 501 (Wanderer 1969), where I note that a variety of sources, including popular notions, provided explanations of riots and the courses they run. Included as one screening device in the selection of "select" variables was the Lieberson and Silverman study (1965).

My use of the Lieberson and Silverman study as a screening device resulted in a second misunderstanding. Spilerman assumed that I sought to replicate it. Enlarging that error, he asserts that I sought to compare my findings with theirs, that I did not do a good job at replication, that I imply my findings are better than theirs, that I suggest my findings for riot severity in 1967 were so good that they explain what was going on in 1913, and finally, that I assume riot severity is the same thing as the presence or absence of a riot. He then instructs us and shows us that these assertions and assumptions are untenable. I agree. Obviously no replication was undertaken, nor did I believe or suggest that an examination of riot severity during one summer is tantamount to a study of rioting over the period 1913-63.

In one place Spilerman asserts that I did not examine the causes of riot severity, while in another place he calls me to task for intimating throughout my paper that there is a causal relation between change in percentage nonwhite and riot severity. Obviously he can be only half correct; in this case, he is first-half correct. I do not raise the issue of causality. 